Evaluating Urban Commute Experience

\title{
Evaluating the Urban Commute Experience: A Time Perception Approach
}

\author{
Yuen-wah Li
}

\begin{abstract}
This article examines the perception of travel time and evaluation of the urban commute experience. It reviews the literature on time perception in psychology, positing perceived travel time as a function of commute characteristics, journey episodes, travel environments, and expectancy. Insights from emerging behavioral economics are drawn to illuminate evaluation of the urban commute experience. The perception-evaluation correspondence presents the potential of a new research approach to travel behavior. A time perception model for evaluating urban commute experience is formulated to accommodate all the posited relationships, with possible moderations by goal attainment, economic values associated, and time urgency. Practical significance of the model is exemplified through its use in explaining mode choice, and as a guide for service planning and design.

\section{Introduction}

Like many other domains of consumer behavior, travel behavior has conventionally been studied with the approach that treats all (including monetary and temporal) aspects of evaluation of a travel experience as a single dimension. A traveler is assumed to view temporal and monetary expenditures alike, and trade one for another on a compensatory basis. In the transportation literature, this single measure is referred to as the "generalized cost," and represents the overall utility (or
\end{abstract}


disutility) of a given commute. The conventional approach, despite its prevalence in transportation research, has devoted inadequate attention to possible distinctive features of temporal experience and expenditures. In consumer research literature, time behavior has received increasing interest over the past decade with the growth of service industries (Carmon 1991). Yet, most of the studies have been conducted primarily with waits (see Durrande-Moreau 1999 for a review) among experiences of time consumption. While waiting time is just one episode of a travel journey, the temporal experience of an urban commuter over the entire journey has rarely been examined in sufficient detail.

Given the fact that daily commutes incur a rather substantial amount of temporal rather than monetary expenditures, investigation of commuters' perceptions of the travel time and their evaluation of the travel experiences is justified. This article discusses the perceived time (i.e., psychological time) vis-à-vis objective clock time that one spends in daily commutes, and examines how it relates to the evaluation of one's travel experience. This proposed research approach is of potential to expand the extant body of knowledge in travel behavior that rests primarily on utilitarian assumptions. It illuminates the human processes, such as perception, underlying the evaluation of travel experiences, rather than the evaluative outcomes per se. The time perception approach is promising not only because it opens up new venues for transportation research, but also because of its implication for the design and planning of transportation systems and the formulation of transport policy. Advances in knowledge and practice as a result of innovative research approaches should be pursued by transport planners and policy-makers who have endeavored to promote the use of public transportation while auto dominance (ownership and use) has been on the rise during the past decades. It is, therefore, particularly worthwhile to focus the research context on public transportation.

This article begins with a brief review of the potential contribution of time perception research to the understanding of a traveler's temporal experience in daily commute. Next, findings from the time perception literature are drawn and discussed as pertinent to the specific context of urban commute, with tentative conclusions proposed in the form of research hypotheses. Then commuter evaluation of travel experience, as inspired by the emerging behavioral decision theory, is examined as a way to explore its possible connection to the perception of commuting time. Based on the tentative conclusions arrived, a framework proposing time perception to be pivotal to evaluation of daily commute experience is ad- 
vanced to guide future empirical validation and further research. Lastly, summary and concluding remarks are presented. As public transportation offers the most diverse form of urban commute experiences, discussion and tentative conclusions are made and drawn with reference to this specific context.

\section{Concepts and Models for Time Perception}

Time perception has a long history in psychology research, dating back to the late 18th century (Roeckelein 2000). Research findings have rendered a valuable source of reference to the understanding of temporal experience of the daily commute. This article presents a selective review of essential concepts and models from major contributors such as Fraisse (1984), Block and Zakay 1996), Boltz (1993), and Hornik (1992).

\section{Time Perception}

The notion of time refers to succession and duration, two different concepts but both related to one's experience of change (Fraisse 1984). The concept of succession involves the perception of two or more different and sequentially organized events, whereas the concept of duration concerns the interval between two successive events. Temporal experience refers to an individual's perceptual physical changes, and the duration in perception is measured against a regular sequence of succession. Time perception, according to Fraisse's conception, is defined as "the attention to, or apprehension of, change through the integration of a series of stimuli and characterized by the ability to conceive of duration, simultaneity, and succession" (Roeckelein 2000, p. 53). It implies that time in perception bears no straightforward relationships to physical time (Fraisse 1984). Hence, the subjective duration experienced by a traveler may be different from the objective time passed.

In fact, this conception lies with the major research interest of time psychophysics that concerns the psychological magnitude of the passage of time (Grondin 2001). Evidences from the psychophysics literature have suggested perceived (subjective) time as a power function of the objective clock time, which is often referred to as "Stevens' law" (Roeckelein 2000; Grondin 2001). Growth of the psychological magnitude of a given duration may be faster than, slower than, or equal to growth of the physical magnitude, subject to the exponent value being greater than, lower than, or equal to unity respectively (Grondin 2001). Eisler (1976), for instance, concluded an exponent value of 0.9 as the best overall approximate for the psychological law applied to time perception. 


\section{Contextual-Change Model}

Several models of psychological time have been advanced in the literature with an attempt to better explain and model psychological time. These models fall into two conventions of research: sensory-process convention and cognitive convention (Block and Zakay 1996). The cognitive approach has prevailed research in psychological time, namely because it offers a more useful way to understand duration experience based on such basic concepts as attention, information processing, and memory (Block and Zakay 1996; Grondin 2001).

Block's (1985) contextualistic model, among cognitive models, proposes that duration experience results from an interaction among:

1. contents of time periods (e.g., empty or filled time);

2. activities during time periods, including temporal and nontemporal attentions;

3. subjects' characteristics (e.g. personality); and

4. temporal behavior (e.g., method of measurement).

Block's model seems to corroborate Fraisse's conception of time perception as related to contextual changes on the one hand, and has elaborated the effect of the contextual changes in terms of attentional processes on the other. Subsequently, Block and Zakay (1996) advanced the contextual-change model that highlighted the importance of temporal attention in determining prospective duration judgments. According to Block and Zakay's model, contextual changes are encoded as time-tags in one's temporal information processing, and hence directly influence duration judgment. However, given the scarcity of one's cognitive resource, nontemporal events taken place in the meantime may compete with temporal cues for attention and processing, and affect duration judgment.

The literature on psychological time has also distinguished between prospective and retrospective duration judgments or estimations (Block and Zakay 1996; 2001). The prospective paradigm refers to the situation in which participants are aware of being engaged in a duration estimation task. Participants may encode temporal information as part of the experience of the time period, and so their judgment is referred to as an "experienced duration." On the other hand, in the retrospective paradigm, participants have no prior knowledge of the duration judgment task. When asked afterward about the duration, participants may retrieve whatever information available in memory. Their judgment is referred to as 
a "remembered duration." As most urban commutes (e.g., going to work) are made regularly, and draw one's attention and estimation of the time spent somehow, the prospective paradigm should be appropriate for the task of judging an experienced duration of commute.

\section{Temporal and Situational Environments}

Corroborating Fraisse' (1984) conception of time as the succession of events over a period, researchers such as Boltz and her colleagues (e.g., Jones and Boltz 1989) have advocated that the structure of events constitutes the temporal environment of duration judgment tasks. The temporal pattern of events (usually in the form of nontemporal information) over a period of time affects the way individuals attend to the events, and thus their determination of duration estimates. Highly coherent events present structural predictability over an arbitrary time span, and hence conducive to future-oriented attending, whereas lowly coherent events contain little predictability, and hence conducive to analytic attending. Individuals adopting future-oriented attending will seek higher order time patterns and generate expectancies about the start and end of a series of events, whereas those adopting analytic attending will turn to adjacent events in organizing ill-structured information. Therefore, in duration judgment tasks, the former group will be biased by the disconfirmation of expected (starting or ending) times, and the latter group by their attention to the amount of local details. Urban commutes of a daily or regular practice should be more conformed to events of high coherence, and so individual travelers are likely to adopt future-oriented attending in their perception of the commute time consumed.

On the other hand, the consumption and perception of time is also situation bound (Hornik 1982; 1984; 1992). Hornik's (1992) research evidence focuses on the effect of affective moods as a situational variable on temporal judgment. It is hypothesized that mood biases temporal judgment by influencing the information to be recalled from memory. Individuals in a good (bad) mood, for instance, are prone to retrieve positive (negative) information, which in turn biases their judgment in a direction congruent with the mood. Alternatively, their judgment may be conceived as a direct consequence of the affective responses, positive or negative, to the stimuli under investigation. Urban commuters moving through hassles of various kinds are liable to fluctuating affective states that influence their temporal judgment of the commute. 


\section{Time Perception in an Urban Commute Context}

It is hypothesized in this article that the perceived travel time of urban commuters (presumably with public transportation) varies with commute characteristics, journey episodes (i.e., ride, wait, access and transfer, service environments), and their expectancies. These relationships are discussed below, making reference to the insights from the time perception literature. The discussion is summarized in the form of research propositions as shown in Table 1.

\section{Table 1. Summary of Propositions for Perceived Travel Time}

\begin{tabular}{|c|c|}
\hline \multirow{2}{*}{\multicolumn{2}{|c|}{ Commute Characteristics }} \\
\hline & Commute Duration \\
\hline P1 & $\begin{array}{l}\text { Commuters will perceive a short duration as being longer, and a long } \\
\text { duration shorter (than the objective clock-time). }\end{array}$ \\
\hline \multicolumn{2}{|c|}{ Commute Stages } \\
\hline $\mathrm{P} 2 \mathrm{a}$ & $\begin{array}{l}\text { Commuters making a given journey involving more commute stages will } \\
\text { perceive the journey time as being longer. }\end{array}$ \\
\hline $\mathrm{P} 2 \mathrm{~b}$ & $\begin{array}{l}\text { Given a constant number of stages, commuters making a journey involving } \\
\text { more evenly distributed commute stages will perceive the journey time as } \\
\text { being longer. }\end{array}$ \\
\hline \multicolumn{2}{|r|}{ Journey Episodes } \\
\hline \multicolumn{2}{|l|}{ Bide } \\
\hline P3 & $\begin{array}{l}\text { Commuters riding on board are likely to percelve a given duration as being } \\
\text { the shortest among the journey episodes. }\end{array}$ \\
\hline \multicolumn{2}{|r|}{ 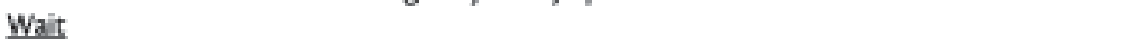 } \\
\hline P4 & $\begin{array}{l}\text { Commuters in wait are likely to perceive a given duration as being the longest } \\
\text { among the journey episodes. }\end{array}$ \\
\hline \multicolumn{2}{|c|}{ Access or Transfer } \\
\hline P5 & $\begin{array}{l}\text { Commuters in access or transfer are likely to perceive a given duration as } \\
\text { being shorter than are those in wait, but longer than are those riding on } \\
\text { board. }\end{array}$ \\
\hline \multicolumn{2}{|r|}{ Travel Environment } \\
\hline \multicolumn{2}{|l|}{ Comfort } \\
\hline & $\begin{array}{l}\text { Commuters will perceive a given duration as being shorter in more } \\
\text { comfortable service environments. }\end{array}$ \\
\hline \multicolumn{2}{|c|}{ Entertainmens } \\
\hline P7 & $\begin{array}{l}\text { Commuters will perceive a given duracion as being shorter in a travel } \\
\text { environment with amusing entertainment provided. }\end{array}$ \\
\hline \multirow{2}{*}{\multicolumn{2}{|c|}{ Commuter Expectation }} \\
\hline & \\
\hline Commute & $\begin{array}{l}\text { Commuters will perceive a given duration as being longer (or shorter) than it } \\
\text { should be, if the duration is longer (or shorter) than one's expected duration. } \\
\text { liability }\end{array}$ \\
\hline P9 & $\begin{array}{l}\text { Commuters will perceive a given duration as being longer for a journey of } \\
\text { lower commute reliability. }\end{array}$ \\
\hline
\end{tabular}




\section{Commute Characteristics}

Commute characteristics include commute duration and commute stage.

\section{Commute Duration}

Dating back to the 19th century, Vierordt, among the pioneers of time psychophysics, conducted experiments on time judgment. His observations are referred to as Vierordt's law (Roeckelein 2000). One conclusion is that "for all categories of time from seconds to years, the same law holds good (i.e., relatively short intervals are lengthened by judgment, and relatively long intervals are shortened" [p. 73]). In regard to a commute experience, a traveler will find a short commute duration longer, whereas a long commute duration shorter, compared to the objective clock-time measurement. This implies that commute duration per se biases the commuter's perceived duration.

\section{Commute Stage}

Urban commuters, particularly those using public transportation, are used to journey interrupts of various kinds (e.g., making transfers in the middle of a trip). These interrupts may be conceived as dividing a single journey into multiple commute stages. Fraisee's principles (Roeckelein 2000) provide insights into the understanding of the effect of staged journeys on perceived travel time. The principles state:

1. A divided interval of time appears to be longer than an empty (standard) interval of the same duration.

2. An interval of time with more divisions appears longer than one with fewer.

3. Of two divided intervals, the one that is evenly divided appears longer than that which is irregularly divided. (p. 124-125).

The first principle supports the prediction that travelers perceive a given commute experience as being longer, when the journey has more commute stages. In other words, from the commuter's perception, interrupts over a journey are time consuming. Fraisee's second principle further suggests that the more commute stages (e.g., transfers) a journey requires, the longer the travel time will be perceived. The third principle, on the other hand, reveals how the distribution of interrupts affects one's experienced duration of a journey. It suggests that, given the same number of interrupts as required by a journey, travelers subject to more evenly distributed stages perceive the travel time as 
being longer. To illustrate, all else being equal, travelers perceive a given twostaged journey comprising two equal-duration segments as being longer, than a short (long) duration segment followed by a long (short) duration segment.

\section{Journey Episodes}

Access, wait, ride, and transfer characterize the episodes of urban commute experience, particularly with public transportation. Perceived duration, however, is likely to vary across the episodes in the light of the relative attention to temporal and nontemporal information (Block and Zakay 1996) and the likely affective state elicited (Hornik 1992) in particular episodes. A description of the general experience in each commute episode follows.

Ride

Given a reasonably stable and comfortable environment, urban commuters in ride episode are likely to be engaged voluntarily or involuntarily in activities such as scheduling daily jobs, reading, day dreaming or napping, and chatting with friends (in person or on phone). These activities demand either a considerable amount of cognitive resource or high involvement by commuters, thus substantially undermining the chance of temporal information processing. The taking place of these activities in concurrence with one's commute characterizes the polychronic time use (i.e., "two or more activities are performed within the same time block, apparently at the same time") (Kaufman, Lane, and Lindquist 1991, p. 393). That is, riding in a setting of reasonable comfort is conducive to polychronic time use which shortens the perceived duration of travel. Urban commuters in ride episode, compared to other journey episodes, are likely to experience the fastest pace of time passage and perceive a given duration as being the soonest.

Wait

Travelers on wait (e.g., for bus service) are subject to unoccupied time, and thus very attentive to the passage of time (Block and Zakay 1996). Temporal cues embedded in the wait context (e.g., repeated passing of unintended bus services or frequent time-checking behaviors by travelers in the same queue), will easily elicit the traveler's temporal attention and temporal information processing. Moreover, the waiting experience will expose travelers to an unfulfilled goal. A discomfort or dissatisfying mood may lead to overestimation of the traveler's temporal judgment. In combination of these effects, urban com- 
muters in wait episode are plausibly perceiving a given duration as being the longest among the journey episodes.

Access and Transfer

Travelers in access or transfer for public transportation will be required to accomplish nontemporal tasks, such as walking, looking for guides, and making their way out of a moving crowd. Subject to the scarcity of cognitive resources, travelers may be inattentive about temporal information, thus not noticing time passage. However, unlike riding on board, access or transfer requires efforts that cannot free travelers for other activities of their choice. Furthermore, travelers may find dealing with access or transfer a stressful task, particularly with an unfriendly arrangement or setting. The negative affect thus aroused may bias the perceived duration upward. As a consequence, urban commuters are likely to perceive a given duration in access or transfer episode as being longer than in ride episode, though shorter than in wait episode.

\section{Travel Environment}

Given the fact that both temporal attention and affect are context dependent, perceived travel time is subject to an array of environmental factors. The effect of comfort and entertainment provided along the journey episodes are examined below.

\section{Comfort}

Comfort has been widely reported in the literature as one of the key dimensions of customer satisfaction for public transportation (see Li 2001 for a review). It is a composite measure of attributes related to service environment, including but not limited to seat availability, smoothness of rides, spaciousness (or loading), air-conditioning (or ventilation), lighting, cleanliness, spatial layout, and furniture and facilities design. A comfortable and pleasant commute environment is, on the one hand, conducive to polychronic time use, and on the other hand, of benefit to mitigate commuting stress and the negative emotions elicited. These effects in combination lead to underestimation of one's temporal judgment.

\section{Entertainment}

Entertainment is provided in commute environments, as in many service settings, as a time filler to direct customer attention to the nontemporal stimuli 
presented so as to undermine temporal information processing. Moreover, amusing entertainment is able to elicit positive moods during one's commute. These effects altogether appear to be conducive to shorten perceived travel time of urban commuters. However, the use of time fillers (e.g., visual and audio entertainment, and music broadcasting as commonly used in public transportation) can lead to mixed results. Entertainment containing overly repetitive or perpetually familiar content has been shown to lengthen one's perceived duration (Kowal 1987), when presenting as temporal cues, or inducing boredom, or both. Also, customer affective responses to musical pieces vary with individual tastes and preferences (North and Hargreaves 1999).

\section{Expectancy}

Urban commute, regardless of the transportation mode used, is likely to be habituated through repeated practice as a routine activity. Conceiving the daily routine as a series of highly coherent events, urban commuters may have adopted future-oriented attending, and generated certain temporal expectations or predictions (Jones and Boltz 1989) for the duration normally required for each journey episode and the journey as a whole for instance. Research by Boltz (Jones and Boltz 1989; Boltz 1993) has indicated that departures from one's temporal expectation led to biased temporal perception. Therefore, urban commuters perceive a given duration of travel as being longer (shorter) if the duration is longer (shorter) than expected, that is when the expectation is negatively (positively) disconfirmed.

In a relatively unstable commute environment (e.g., frequent road congestion for car commuters or public transportation with frequent delays), travelers may have difficulty apprehending temporal expectancy, making the commute an uncertain task. Given the correlation between task uncertainty and overestimated duration (Boltz 1998), an urban commute taking place in a rather unpredictable setting is expected to result in longer perceived journey time.

\section{Evaluation of the Urban Commute Experience}

Traditional decision theory presumes people make choices based on "decision value" (i.e., the predicted outcome for future experiences with perfect accuracy and option evaluation) (Kahneman and Tversky 1984). Emerging behavioral economics, in contrast, recognizes the important role of "experience value" in the decision-making process. It assumes decision-makers to be hedonic and concerned about "the degree of pleasure or pain, satisfaction or anguish in the actual experience of an outcome" (p. 170), instead of being utilitarian and concerned 
about the anticipated outcome. In this article, evaluation refers to the "experience value" that commuters rate toward a given urban commute experience. The following sections examine evaluation of the urban commute experience by commute characteristics, journey episodes, and expectancy. The extant body of literature on behavioral economics, particularly the Prospect theory (Kahneman and Tversky 1979), is taken as the primary source of reference, with support from the findings of transportation research where appropriate. Tentative conclusions are summarized as propositions in Table 2.

\section{Table 2. Summary of Propositions for Evaluation of the Urban Commute Experience}

\begin{tabular}{|c|c|}
\hline & Commute Characteristics \\
\hline Comr & ite Duration (asymmetric effect) \\
\hline P10 & $\begin{array}{l}\text { Commuter value of time will exhibit a convex functiont the longer the duration, } \\
\text { the lower the marginal value of time. }\end{array}$ \\
\hline Comr & ate Stages (segregation effect) \\
\hline P11a & $\begin{array}{l}\text { Commuters making a given journey inwolving multiple commute stages will suffer } \\
\text { segregated losses: the more stages involved, the greater the losses in accumulation. }\end{array}$ \\
\hline P11b & The more evenly distributed the stages, the greater the losses in accumulation \\
\hline & Journey Episodes \\
\hline Peak- & d (peak-end effect) \\
\hline P12a & $\begin{array}{l}\text { Commuters will appraise specific moments of a given journey that arouse strong } \\
\text { negative affect as incurring greater losses (e.g., wait, transfer, or ride without a } \\
\text { seat), than other moments of the journey. }\end{array}$ \\
\hline & $\begin{array}{l}\text { Commuters will value disproportionately the end moment of a journey, during } \\
\text { which goal attainment will be evaluated, and intense emotionality will be elicited. }\end{array}$ \\
\hline Durat & n (duration neglect) \\
\hline P13 & $\begin{array}{l}\text { Commuters will sometimes value the duration of an episode as negligible (e.g, ride } \\
\text { in a reasonably comfortable environment), as compared to the peak and end } \\
\text { moments. }\end{array}$ \\
\hline & Expectancy \\
\hline Comr & ter Reference (reference effect) \\
\hline & $\begin{array}{l}\text { Commuters will evaluate temporal gain or loss about an expected or habituated } \\
\text { duration as the reference point. }\end{array}$ \\
\hline P14b & Commuters will rate temporal losses as more important than temporal gains. \\
\hline Comr & ite Reliability (certainty effect) \\
\hline P15 & $\begin{array}{l}\text { Commuters will rate a reliable (es. punctual, adhered to schedule) service or a } \\
\text { stable commute as disproportionately high. }\end{array}$ \\
\hline
\end{tabular}




\section{Commute Characteristics}

\section{Commute Duration}

The Prospect theory suggests that value is assessed with respect to gains or losses, and the value function generally exhibits a concave shape in the gain domain and a convex shape in the loss domain (Kahneman and Tversky 1979). To the extent that commuting time is considered a loss, the value function of commute duration is expected to exhibit convexity. Other things being equal, the experience value for a given urban commute is expectedly subject to diminishing sensitivity of the total travel duration: the longer (shorter) the commuting time, the lower (higher) its marginal value. Findings from the transportation research literature also lend support to the convexity of the value function of commute duration (e.g., Kjoerstad and Renolen's [1996] valuation of travel time in five Norwegian towns, and Small and colleagues' [Small, Noland, Chu, and Lewis 1999] willingness to pay study for reduced congestion delay for various trip lengths in the United States).

\section{Commute Stages}

Travelers making a multistaged journey may be conceived as subject to combined prospects, in which losses are segregated by commute stages (Kahneman and Tversky 1979). Given a convex loss function, the segregated losses in accumulation shall loom larger for a multistaged journey, compared to an equivalent journey of no or fewer commute stages. Furthermore, for a constant number of commute stages over a journey, the segregated losses in accumulation will be greater if those stages are more uniformly distributed temporally. Though these predictions are by and large consistent with the decision behavior based on monetary evaluation, urban commuters as consumers of time are expected to demonstrate an even stronger propensity to integrate losses (Leclerc, Schmitt, and Dube 1995), say by reducing the number of commute stages. Kjoerstad and Renolen (1996) reported a strong preference for direct trips without transfer, even if the journey time was longer. In two Norwegian cities, direct connection without transfer was rated 1.8 to 5.0 times as valuable for a journey requiring a transfer with a 5-minute waiting time, or 2.5 to 9.2 times as valuable for the one with a transfer with 10 minutes waiting time. 
Evaluating Urban Commute Experience

\section{Journey Episodes}

Peak Episode

Kahneman's research (1999) notes that "retrospective evaluations of affective episodes are strongly influenced by the affect experienced at singular moment" (p. 2). As far as urban commute experience is concerned, some singular moments along the journey episodes may be more affectladen than the others (e.g. ride without seats, waiting on-street unsheltered). These instances are likely to arouse strong negative affect, and return the most regretful value (i.e., the greatest loss) to the commuters, characterizing "the most extreme affect experienced" (p. 6) moment(s) or the "peak" snapshot(s) of a journey. For instance, in six Norwegian towns, travel time standing was found to be very "expensive" - rated 2.0 to 3.0 times as undesirable for travel time seated (Kjoerstad and Renolen 1996). Walking access, waiting, and transfer were rated 2.0 to $2.5,1.5$ to 3.4 , and 1.3 to 2.9 times, respectively, as undesirable for travel time seated. Recent research studies for the United States revealed the value of out-of-vehicle times to be 2 to 3 times of that of in-vehicle times (U.S. Department of Transportation 1997; Bhat 1998), remaining in order with study findings reviewed in Cherlow (1981). Riding with discomfort and out-of-vehicle episodes, such as wait or access, are likely to be the peak experiences during an urban commute.

End Episode

On the other hand, evaluation as to whether the journey's goal can be attained will usually be processed near the end of a trip. This near-end evaluation may again lead to an extreme affect as at the peak episode, characterizing the "end" snapshot of a journey (Kahneman 1999). For example, failing to get to work on time is very likely to elicit a commuter's intense negative mood. Such strong emotion can overwhelm one's evaluation of the commute, and the entire journey may be viewed as being overly negative, even though all previous episodes are satisfying. The end-episode effect may offer partial support to the notion of higher willingness to pay for more reliable arrival time to work than nonwork trips in the United States (Small et al. 1999).

Duration Neglect

The "peak" and "end" snapshots, as Kahneman (1999) suggested, determine the overall evaluation of a given experience, and undermine the significance of the experience duration. This undermining is referred to as "duration 
neglect" in the behavioral decision literature. Duration neglect suggests that, given the intense emotionality of certain singular moments along a journey, the duration is likely to be negligibly valued, if not totally neglected, in one's evaluation. Ariely and Carmon (forthcoming) recently set out two conditions for duration neglect to be in place:

1. when the duration as an attribute is not attended to; and

2. when the duration of the experience is inherent to the experience.

Though duration is inherent to urban commute experience, commuters will somehow care about the duration (e.g., for scheduling or comparing services). It is therefore unlikely that duration neglect will take place in full range in the urban commute context.

\section{Expectancy}

\section{Commuter Reference}

As mentioned above, through repeated practice, urban commuters have generated certain temporal expectancies. These expectancies are encoded in a commuter's mental account as costs for routine (temporal) transactions, rather than occasional losses (Thaler 1985). They serve as a reference context for one's assessment of temporal gains (time saved) or losses (time wasted). Given the S-shape of the value function about a given reference point (Kahneman and Tversky 1979), temporal losses shall loom larger than temporal gains with reference to a commuter's expectation.

Commute Reliability

Prospect theory (Kahneman and Tversky 1979) predicts that decisionmakers rate the importance of sure gains as more valuable than probable (i.e., uncertain) gains, contrasting traditional decision theory that assumes evaluation based on expected value criteria. Leclerc, Schmitt, and Dube (1995) further contend with empirical evidence that individuals are more highly risk averse toward temporal resources, compared to monetary resources. One reason given is the low transferability of temporal resources. The certainty effect in regard to temporal resources will be considered more appealing than monetary resources. As for the urban commute, the certainty effect is likely to imply a disproportionately high value attached to a stable commute, be it a reliable service (in terms of punctuality and adherence to schedule for instance) or a flow traffic. The predictability associated with a stable commute allows urban commuters to plan how to use their temporal resources more effectively. Kjoerstad and Renolen's 
(1996) report revealed that passengers in Oslo, Norway, had strong preferences for highly reliable services, and considered even short delays a problem.

\section{Time Perception Model of Evaluating the Urban Commute Experience}

\section{Correspondence Between Perception and Evaluation}

The propositions set out for time perception in the urban commute context and temporal evaluation of the urban commute experience are outlined and compared in Table 3. The comparison exhibits high correspondence between the two proposition sets. The correspondence reminisces the psychological origin of the emerging behavioral economics, particularly the Prospect theory. The S-shaped value function, for instance, seems to reverberate Stevens' power law as proposed in the psychophysics literature (Roeckelein 2000).

Table 3. Comparison of Propositions Sets for Perceived Travel Time and Evaluation of the Urban Commute Experience

\begin{tabular}{|c|c|c|}
\hline Variables & Perceived Travel Time & $\begin{array}{l}\text { Commute Experience } \\
\text { Evaluation }\end{array}$ \\
\hline \multicolumn{3}{|c|}{ Commute Characteristics } \\
\hline Duration & $\begin{array}{l}\text { Longer for short duration; } \\
\text { shorter for long duration }\end{array}$ & $\begin{array}{l}\text { Convex loss function } \\
\text { (asymmetric effect) }\end{array}$ \\
\hline Stages & Longer for a multiple-staged journey & Segregated losses \\
\hline \multicolumn{3}{|c|}{ Journey Episodes } \\
\hline Peak & $\begin{array}{l}\text { Longest for waits, transfers, or uncomfortable } \\
\text { rides }\end{array}$ & Peak snapshot \\
\hline End & - & $\begin{array}{l}\text { End snapshot } \\
\text { (related to journey } \\
\text { goal attainment) }\end{array}$ \\
\hline Duration & Shortest for rides (with reasonable comfort) & Duration neglect \\
\hline \multicolumn{3}{|c|}{ Expectancy } \\
\hline $\begin{array}{l}\text { Commuter } \\
\text { Expectations }\end{array}$ & $\begin{array}{l}\text { Longer when longer than expected } \\
\text { shorter when shorter than expected }\end{array}$ & $\begin{array}{l}\text { Temporal loss } \\
\text { looming larger than } \\
\text { temporal gain } \\
\text { (reference effect) }\end{array}$ \\
\hline $\begin{array}{l}\text { Commute } \\
\text { Reliability }\end{array}$ & Longer for low-commute reliability & Certainty effect \\
\hline
\end{tabular}


Furthermore, the correspondence suggests a more coherent relationship with one's evaluation for the perceived rather than the physical stimuli, despite the departure of the perceived reality from the physical reality which Tversky referred to as "perceptual illusion" (McFadden 1998). In other words, subjective time, however illusive, may be rather informative of one's evaluation of a commute experience, as compared to the objective clock time. In fact, research studies on waiting times have offered consistent evidence for the connection of increased perceived (wait) time with more negative customer evaluation (e.g., Katz, Larson, and Larson 1991; Pruyn and Smidts 1998; Antonides, Verhoef, and van Aalst 2002).

\section{The Model}

This section discusses the development potential of a research approach to commute behaviors that places perceived travel time as central to one's evaluation of a commute experience. A tentative model is proposed, linking the hypothesized factors to one's perception of travel time, and hence commute experience evaluation, as represented by the black solid lines in Figure 1. More specifically, perceived travel time is expected to vary with four factor categories:

1. commute characteristics (objective duration and number of commute stages);

2. journey episodes (e.g., commuters are riding or transferring);

3. service or commute environment (comfort and the provision of entertainment or the quality of entertainment provided); and

4. expectancy (commuter expectancy and service reliability).

Furthermore, the perceived travel time determined is expected to be predictive of one's evaluation of the commute experience.

Despite the postulated importance of perceived travel time to commute experience evaluation, the proposed model accommodates potential direct impacts of the identified factor categories on a commuter's evaluation. These direct contributions may be conceived as support for the notion of duration neglect as discussed above. The model, however, leaves open for empirical evaluation the question as to the extent of explained variances on the commute experience evaluation to be accounted for by the four factor categories with and without the mediation of perceived travel time. 


\section{Figure 1: Time Perception Model of Evaluating the Urban Commute Experience}

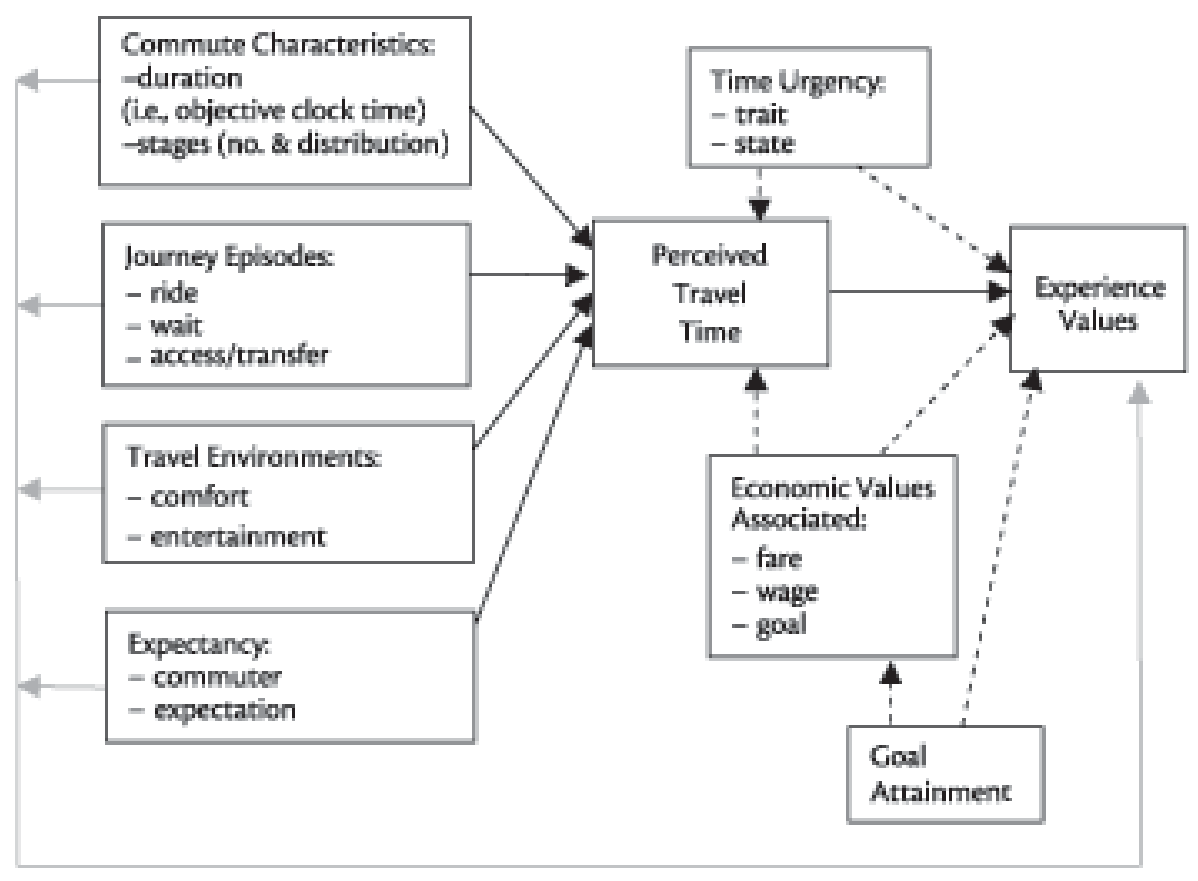

\section{Moderators for Perception-Evaluation Link}

There may be other constructs at play (e.g., goal attainment, economic values, time urgency) that influence commuters' perceptions, or moderate the perception-evaluation link, as represented by the dotted lines in Figure 1.

\section{Goal Attainment}

As mentioned above, goal attainment is usually assessed near the end of the journey, and the assessment will possibly bring about intense emotions that moderate the perception-evaluation link. On the other hand, as the goal of most urban commutes is associated with production or economic activities (e.g., going to work), goal attainment is related to economic gains or losses, which lead to corresponding changes in experience value. 


\section{Economic Values}

The economic costs or values associated with a commute also influence a commuter's evaluation. For one, fare represents the monetary payoff for the chosen public transportation modes. Wage reflects the economic cost of the time consumed, as most economists assumed (e.g., Becker 1965). Part of the economic values may also be related to goal attainment (e.g. monetary penalty for late-comers). Antonides et al.'s work (2002) presents the moderating effect of monetary cost of time on the perception-evaluation link for a telephone wait setting.

Time Urgency

While perception and evaluation involves subjective judgment of individual commuters, individual differences should have their part to play. In particular, time urgency as a personality trait or a personality state (Koslowsky, Kluger, and Reich 1995) is expected to affect time perception and experience evaluation of individual commuters. As a personality trait, time urgency refers to an individual's disposition about time in general (e.g., Type A behavior), whereas as a personality state, it reflects specific time demands of the external environments (e.g., getting to work on time).

\section{Implications}

\section{Explaining Modal Choice}

The postulated time perception model is of potential contribution to a better understanding of travel behavior, such as the notion of auto dominance and the preference for bus over rail as exemplified below.

\section{Auto Dominance}

The private car has remained the prevailing mode of transportation for the urban commute. In 1995, the automobile accounted for 43 percent of passenger kilometers worldwide (Pucher 1999). The time perception model of commute evaluation may well explain the notion of auto dominance in regard to a commuter's perception of travel time. An auto commute is attractive in most courses of perceived travel time, compared to a public transportation commute. It is most likely a door-to-door service, thus minimizing the number of commute stages. It spends time predominantly on the ride episode, usually with seats secured and even entertainment (e.g., music) of the commuter's choice. It demands the commuter's (i.e., driver's) continuous 
attention to road conditions and motor operation, rather than temporal cues or information, and hence exploits the cognitive resource for nontemporal information processing. Also, it avoids the temporal and monetary losses due to unreliable public transportation services. All these may result in a given journey perceived as shorter for an auto commute, and hence the commute experience to be more positively evaluated than for a commute with public transportation. Though people intending to travel by car to save time are not necessarily objectively justified, their savings in the experienced time and positive evaluation associated may be arguably real (Hjorthol 2001).

Bus Versus Rail

Of the public transportation modes, bus and coaches are the most preferred. In 1995, bus and coaches recorded a 20 percent modal split of the world's passenger transport in terms of passenger kilometers, compared to only a 6 percent split for rail-based modes (Pucher 1999). The notion of a larger modal split for bus than rail remains valid for well-developed countries such as the United States, where modal shares (in passenger-miles) of bus and rail were 1.1 percent and 0.5 percent, respectively, in 1997 . Though there are many reasons (e.g., the investment required) to the relative prevalence of bus over rails, the time perception model potentially offers a good account. For instance, bus is usually more accessible than rail and is likely to entail fewer commute stages or transfers for urban commuters. On the other hand, bus is more likely to offer commuters with seats than is rail, and hence more conducive to polychronic time use (Kaufman et al. 1991). Therefore, though the objective travel time for a given journey may be longer for bus than rail, the perceived travel time can be shorter for a commuter with bus than rail, leading to a more desirable evaluation of the bus mode. The reliability of bus services, however, is more susceptible to road conditions, and in some cases renders bus to be less preferred than rail in view of possible temporal and monetary losses as a result of service delays.

\section{Guiding Service Planning and Design}

The proposed time perception model of evaluating commute experience is intended not only to provide a better understanding of urban commute behaviors, but also to be of practical value to the planning and design of a public transportation system. Of the potential contributions, it highlights perceptual vis-à-vis physical aspects in service planning and design for public transportation. The conven- 
tional approach to service planning design has been obsessed with such efficiency criteria as maximum flows and shortest paths (travel durations). The proposed approach, however, calls for the creation of commute patterns conducive to polychronic time use, and the provision of reliable services and a pleasant travel environment. It also lends support to the potential of developing walking as a desirable transportation mode.

Transfers

Most public transportation networks are designed with an overwhelming concern on efficiency, resulting in transfer points of various kinds for intramodal or intermodal connections. It is inevitable that, in their journey with public transportation, urban commuters go through more than one commute stage, and experience the transfer episode(s). The tolerance of urban commuters in regard to the number of transfers required, and their temporal distribution, over a journey, however, has yet to be determined. Obviously, travel disrupted by frequent transfers hampers commuters' polychronic time use. Travel requiring a transfer midway keeps commuters attentive for half of the journey and the related temporal information. It appears, for instance, that the number of transfers required for a journey to work should be limited to two, though more transfers may be acceptable for commutes of other purposes (e.g., leisure). On the other hand, a congenial design of transfer points reduces the extent of perceived contextual changes, and hence the perceived passage of time during the transfer episode. Transfer points so designed, among others, may require just a brief access from one line (mode) to another, and have an integrated in and out for all modes available.

\section{Reliable Services}

The time perception model suggests that unreliable or disconformed services are evaluated as extremely undesirable by urban commuters, because the travel time is perceived as unreasonably long. The negative evaluation is likely to be coupled with failure in goal attainment, for instance, due to delayed arrivals. This is in contrast with the auto commute experience in which, under normal road conditions, the driver has control over the departure time, route choice, speed used, and even the arrival time, as conformed with the commuter's expectation. The comparative disadvantage on commute reliability or predictability of public transportation may be one reason that continues to motivate urban commuters to use autos. Service reliability is, therefore, ex- 
tremely important in attracting urban commuters to public transportation, though not equally important in drawing auto commuters. However, transport operators obsessed with efficiency are tempted to publicize the best achievable service level or the shortest travel time, ignoring the adverse impact of variability on commuters' perceived duration and service evaluations. Whereas, planners having regard to perceptual elements should seek to manage commuters' expectations, say by presenting realistic or rather conservative estimates of service information on the one hand, and give variability a disproportionate weight in service planning and design on the other.

Travel Environment

A comfortable and pleasant travel environment is conducive to polychronic time use, and reduces commute stress and hence a negative mood. Such an environment helps to shorten perceived travel time, and bring about positive evaluation of the commute experience. In regard to the determination of service levels for public transportation, for instance, planners overwhelmed with doing more for less are tempted to pack as many passengers in a given compartment as the safety requirement would allow at the expense of commuter's experiences. However, it is recommended to establish target load levels for different periods of operation that balance efficiency and perceptual concerns. On the other hand, congeniality, suggested as the guiding principle for the design of transfer points, should also be adhered to wherever possible in the design of other commute environments (e.g., wait and access areas). It encompasses the logistic aspects as well as perceptual factors such as temperature and color tones. It should be noted that while entertainment in public transportation settings is intended to distract commuters' attention from temporal information, reaction toward the entertainment used, be it visual or audio, depends very much on individual taste. Thus, the effect is rather unpredictable. A boring film, for example, may be a driver to attend to time passage, or to go napping while traveling. It is, therefore, difficult to generalize the use of entertainment as a tool for managing perception.

Walking as a Mode

Walking as a nonmotorized transport mode accounted for 17 percent passenger kilometers made among the world's passenger transport in 1995 (Pucher 1999). Walking has met with increasing recognition by policy-makers as an important transportation mode in both the United States and Euro- 
pean countries. While the time perception model suggests that a short commute is likely to be perceived as longer, walking presents potential to reduce perceived travel time particularly well for relatively short-distance travels, say within $800 \mathrm{M}$. Unlike commutes with public transportation, walking demands the traveler's continuous attention to the environment and motor operation. This may help divert a traveler's attention from temporal information to nontemporal goals (e.g., a certain building ahead), thus reducing the perceived duration of travel. On the other hand, walking, like an auto commute, allows travelers (commuters) to control departure time, route choice, and arrival time, possibly leading to conformed expectation in travel time. It is equivalent to, and as valuable as, a highly reliable transportation mode, particularly for short-distance travels. However, the walking environment provided, including facilities (e.g., air-conditioning), traffic priority, pedestrian safety measures, etc., is essential to promoting walking as a desirable alternative mode. Policy-makers in this pursuit should endeavor to create a pleasant and safe walking environment.

\section{Summary and Concluding Remarks}

This article has attempted to contribute an alternative approach to the research of transportation behavior which has been drawing predominately on conventional decision theory and particularly random utility models. It examined the subjective perception of travel time spent for the urban commute and evaluation of the commute experience. In view of the long history of time perception in psychology research, the time perception literature was reviewed, particularly psychophysics and cognitive models of time perception, as pertinent to the context of the urban commute. Through the literature review, perceived travel time of urban commuters was hypothesized to be contingent with (1) commute characteristics (duration and the number and distribution of commute stages); (2) journey episodes (ride, wait, and access and transfer); (3) travel environments (condition of comfort and entertainment provided); and (4) expectancy (commuter expectation and commute reliability).

The article has also made reference to the emerging behavioral decision theory, particularly Kahneman and Tversky's Prospect theory, in the examination of the evaluation of the urban commute experience. It appeared that (1) asymmetric and segregation effects was relating evaluation to commute characteristics; (2) peak-end effect and duration neglect (less likely though) were at play to affect evaluation through journey episodes; and (3) reference and certainty effects ac- 
counted for the impact of commuter expectation and commute reliability on evaluation. Furthermore, the hypothesized relationships exhibited high correspondence with those identified for perceived travel duration. A time perception model of evaluating urban commute experience was proposed, accommodating all the posited relationships, and placing perceived travel time as central to the evaluation of a given urban commute experience. Some possible moderators for the link between perceived travel time and evaluation were also postulated and discussed, namely goal attainment, economic values associated, and time urgency.

The proposed model not only suggested an innovative approach for transportation research, but also to be of descriptive and prescriptive value for practitioners. It was applied to explain mode choice behaviors, namely auto dominance and the preference of bus over rail, from the perspective of perceived duration. More importantly, it drew the attention of transport planners and policy-makers to the perceptual vis-à-vis physical aspects of transportation system. Transfers, service reliability, travel environment, and walking as a transport mode were highlighted and discussed.

Some limitations of this article are acknowledged. The literature reviewed was by no means exhaustive of the total body of the research in psychology and behavioral economics. Also, research studies adopting the behavioral economics approach to the investigation of transport behavior are parsimonious. This article may be among the few of its kind. In addition, the hypothesized relationships of the model are tentative, and yet to be confirmed by empirical evaluation. There should be much room for modification and development based on the result of empirical examination. Apparently, it is remote to apply behavioral decision theory to inquire transport choice behavior, to the same extent as conventional decision theory is applied. Despite these limitations, this article hopefully presents a pioneering attempt. 
Journal of Public Transportation, Vol. 6, No. 4, 2003

\section{References}

Antonides, G., P. C. Verhoef, and M. van Aalst. 2002. Consumer perception and evaluation of waiting time: A field experiment. Journal of Consumer Psychology 12 (3): 193-202.

Ariely, D., and Z. Carmon, Z. Forthcoming. Summary assessment of experiences: The whole is different from the sum of its parts. In G. Loewenstein, D. Read and R. Baumeister, eds., Time and Decision: Economic and Psychological Perspectives on Intertemporal Choice. NY: Russell Sage Foundation Press.

Becker, G. 1965. A theory of the allocation of time. The Economic Journal 75: 299, 493-517.

Bhat, C. R. 1998. Accommodating variations in responsiveness to level-of-service measures in travel mode choice modeling. Transportation Research, A 32 (7): 495-507.

Block, R. A. 1985. Contextual coding in memory: Studies of remembered duration. In J. A. Michon and J. L. Jackson, eds., Time, mind, and behavior. Hillsdale, NJ: Erlbaum, p. 1-35.

Block, R. A., and D. Zakay. 1996. Models of psychological time revisited. In H. Helfrich ed., Time and Mind. Kirkland, WA: Hogrefe \& Huber, 171-195.

Block, R. A., and D. Zakay. 2001. Retrospective and prospective timing: Memory, attention, and consciousness. In C. Hoerl and T. McCormack, eds., Time and Memory: Issues in Philosophy and Psychology. New York: Oxford University Press, 59-76).

Boltz, M. 1993. Time estimation and expectancies. Memory and Cognition 21 (6): 853-863.

Boltz, M. 1998. Task predictability and remembered duration. Perception and psychophysics 60 (5): 768-784.

Carmon, Z. 1991. Recent studies of time in consumer behavior. Advances in Consumer Research 18: 703-705.

Cherlow J. R. 1981. Measuring values of travel time savings. Journal of Consumer Research 7: 360-371.

Durrande-Moreau, A. 1999. Waiting for service: Ten years of empirical research. International Journal of Service Industry Management 10 (2): 171-189. 
Eisler, H. 1976. Experiments on subjective duration 1878-1975: A collection of power function exponents. Psychological Bulletin 83: 185-200.

Fraisse, P. 1984. Perception and estimation of time. Annual Review of Psychology 35: $1-36$.

Grondin, S. 2001. From physical time to the first and second moments of psychological time. Psychological Bulletin 127 (1): 22-44.

Hjorthol, R. 2001. Gendered aspects of time related to everyday journey. ACTA Sociologica 44: 37-49.

Hornik, J. 1982. Situational effects on the consumption of time. Journal of Marketing 46: 44-55.

Hornik, J. 1984. Subjective vs. objective time measures: A note on the perception of time in consumer behavior. Journal of Consumer Research 11: 615-618.

Hornik, J. 1992. Time estimation and orientation mediated by transient mood. Journal of Socio-Economics 21 (3): 209-227.

Jones, M. R., and M. Boltz. (1989). Dynamic attending and responses to time. Psychological Review 96 (3): 459-491.

Kahneman, D. 1999. Evaluation by moments: Past and future. Retrieved July 19, 2001, from University of Massachusetts Web site: http://www.umass.edu/ preferen/wpapers/wp-danielk1.pdf.

Kahneman, D., and A. Tversky. 1979. Prospect Theory: An analysis of decisions under risk. Econometrica 47: 263-291.

Kahneman, D., and A. Tversky. 1984. Choices, values, and frames. American Psychologist 39: 341-350.

Katz, K. L., B. M. Larson, and R. C. Larson. 1991. Prescription for the waiting-in-line blues: Entertain, enlighten, and engage. Sloan Management Review: 44-53.

Kaufman, C. F., P. M. Lane, and J. D. Lindquist. 1991. Exploring more than 24 hours a day: A preliminary investigation of polychromic time use. Journal of Consumer Research 18: 392-401.

Kjoerstad, K. N., and H. Renolen. 1996. Better public transport passengers' valuation of time and service improvements. Paper presented at PTRC annual meeting 1996. 
Journal of Public Transportation, Vol. 6, No. 4, 2003

Koslowsky, M., A. N. Kluger, and M. Reich. 1995. Commuting stress: Causes, effects, and methods of coping. New York: Plenum Press.

Kowal, K. 1987. Apparent duration and numerosity as a function of melodic familiarity. Perception and Psychophysics 42 (2): 122-131.

Leclerc, F., B. H. Schmitt, and L. Dube. 1995. Waiting time and decision making: Is time like money. Journal of Consumer Research 22 (1): 110-119.

Li, Y. W. 2001. Service quality of public transport services. Unpublished manuscript.

McFadden, D. 1998. Rationality and economists? Retrieved July 11, 2001, from University of California, Berkeley, Econometric Laboratory website: http:// emlab.berkeley.edu/eml/nsf97/mcfadden.pdf.

North, A., and D. J. Hargreaves. 1999. Can music move people? The effects of musical complexity and silence on waiting time. Environment and Behavior 31 (1): 136-149.

Pruyn, A., and A. Smidts. Effects of waiting on the satisfaction with the service: Beyond objective time measures. International Journal of Research in Marketing 15: 321-334.

Pucher, J. 1999. Transportation trend, problems, and policies: An international perspective. Transportation Research Part A 33 (7-8): 493-503.

Roeckelein, J. E. 2000. The concept of time in psychology: A resource book and annotated bibliography. Westport, CT: Greenwood Press.

Small, K., R. Noland, X. Chu, and D. Lewis. 1999. Valuation of travel-time saving and predictability in congested conditions for highway user-cost estimation. National Cooperative Highway Research Program Report 431. National Academy Press, Washington, DC.

Thaler, R. H. 1985. Mental accounting and consumer choice. Marketing Science 4 (3): 199-214.

U.S. Department of Transportation. 1997. The value of saving travel time: Departmental guidance on the evaluation of travel time in economic analysis. Memo. U.S. Department of Transportation. 


\section{About the Author}

YuEN-wAH LI (yuenwahli@sinaman.com) is a DBA candidate at Argosy University/ Sarasota. Mr. Li received an MA in economics from the University of Oklahoma (Norman) and a BA in quantitative analysis for business at City University of Hong Kong.

Since 1993, Mr. Li has served as assistant manager for planning and development at Hong Kong's Kowloon Motor Bus Co. Ltd., one of the world's largest public bus companies owned by private enterprises. 